\title{
Vivências entre acadêmicos e técnicos de enfermagem: estamos contribuindo?
}

\author{
Experiences between nursing academics and nurse technicians: are we contributing?
}

Vivencias entre académicos y técnicos de enfermería: ¿estamos contribuyendo?

Jéssica Gonçalves da Cruz ${ }^{1 *}$, Camila Santana Domingos ${ }^{1}$, Luana Vieira Toledo', Marilane de Oliveira Fani Amaro', Patrícia de Oliveira Salgado'.

\section{RESUMO}

Objetivo: Compreender a percepção e os desafios vivenciados pelos técnicos de enfermagem acerca da inserção dos acadêmicos de enfermagem no cenário de trabalho. Métodos: Estudo qualitativo realizado com 18 técnicos de enfermagem atuantes nas equipes de Estratégias Saúde da Família de um município da Zona da Mata Mineira. A coleta de dados ocorreu entre os meses de setembro a novembro de 2019 através de entrevistas com roteiro semiestruturado. Os dados foram submetidos à Análise de Conteúdo. Resultados: A maioria dos entrevistados eram mulheres, com tempo médio de vivência em aulas práticas de 5 anos. O conteúdo das entrevistas originou três categorias temáticas: "O que a prática ensina?" "Integração ensino-serviço: uma via de mão dupla" e "Acadêmicos x técnicos de enfermagem: desafios vivenciados". Conclusões: Depreende-se que os técnicos de enfermagem percebem que a inserção dos acadêmicos de enfermagem no campo prático promove benefícios para pacientes, acadêmicos e profissionais, a partir do desenvolvimento de atividades já inseridas no serviço e da implementação de novas propostas de atuação. Todavia, alguns fatores individuais relacionados aos próprios acadêmicos e fatores externos relacionados à infraestrutura e organização do processo de trabalho, podem influenciar a percepção dos técnicos de enfermagem.

Palavras-chave: Técnicos de enfermagem, Estudantes de enfermagem, Atenção primária à saúde, Enfermagem, Aprendizagem na prática.

\section{ABSTRACT}

Objective: To comprehend the perception and the challenges experienced by nurse technicians with regard to the inclusion of nursing academics in the work environment. Methods: A qualitative study was performed with 18 nurses who work in the Family Health Strategy teams in a municipality located in Zona da Mata, a region in Minas Gerais. Data collection was carried out between the months of September and November 2019 through interviews based on a semistructured script. The data were subjected to Content Analysis. Results: Most interviewees were women whose average length of experience in practical classes was 5 years. The content of the interviews resulted in three thematic categories: "What does practice teach?" "Teaching-service integration: a two-way street" and "Students vs. Nurse technicians: experienced challenges". Conclusion: It follows that the Nurse technicians perceive that the inclusion of nursing academics in the practical field work promotes benefits to patients, academics and professionals, resulting from the development of activities that had already been inserted into the service and from the implementation of new action proposals. However, some single factors related to the very academic principles and external factors related to the infrastructure and organization of the working process can influence the perception of Nurse technicians.

Keywords: Nurse technicians, Nursing students, Primary health care, Nursing, Learning in practice.

\section{RESUMEN}

Objetivo: Comprender la percepción y los desafíos vivenciados por los técnicos en enfermería acerca de la inserción de los académicos de enfermería en el escenario de trabajo. Métodos: Estudio cualitativo realizado con 18 técnicos de enfermería actuantes en los equipos de Estrategia de la Salud de la Familia en un municipio de la Zona da Mata de Minas Gerais. La recogida de datos ocurrió entre los meses de septiembre y noviembre de 2019 a través de entrevistas con un cuestionario semiestructurado. Los datos fueron sometidos al Análisis de Contenido. Resultados: La mayoría de los entrevistados eran mujeres con tempo medio de vivencia en clases prácticas de 5 años. El contenido de las entrevistas originó tres categorías temáticas: “¿Qué enseña la práctica?” "Integración enseñanza-servicio: una vía de doble sentido" y "Académicos vs. técnicos en enfermería: desafíos vivenciados". Conclusión: Se concluye que los técnicos de enfermería perciben que la inserción de los académicos de enfermería en el campo práctico promueve beneficios para los pacientes, los académicos y los profesionales, a partir del desarrollo de actividades ya inseridas en el servicio y de la implementación de nuevas propuestas de actuación. Sin embargo, algunos factores individuales relacionados con los propios académicos y factores externos relacionados con la infraestructura y a la organización del proceso de trabajo pueden influenciar la percepción de los técnicos en enfermería.

Palabras clave: Técnicos en enfermería, Estudiantes de enfermería, Atención primaria de salud, Enfermería, Aprendizaje por la práctica.

1 Universidade Federal de Viçosa (UFV), Viçosa - MG *E-mail: jessica.g.cruz@ufv.br

SUBMETIDO EM: 9/2020

ACEITO EM: 10/2020

PUBLICADO EM: 12/2020

REAS/EJCH | Vol.12(12) | e5164 | DOI: https://doi.org/10.25248/reas.e5164.2020 Página 1 de 8 


\section{INTRODUÇÃO}

A enfermagem é uma categoria profissional que se destaca, tanto pelo número de profissionais, como pela abordagem ininterrupta e direta ao paciente (DUARTE JM e SIMÕES AL, 2015). Segundo Conselho Federal de Enfermagem, o número total de profissionais de enfermagem (auxiliares, técnicos, enfermeiros e obstetrizes) no Brasil é de 2.151.114. Destes, 1.214.76 corresponde aos técnicos de enfermagem, número significativo que representa aproximadamente $56,44 \%$, demonstrando a importância desta profissão em todas as áreas de atuação (COFEN, 2019).

Um dos locais que oferecem maior autonomia para atuação da enfermagem é a Atenção Primária a Saúde (APS), que compreende a Estratégia Saúde da Família (ESF). A APS se configura como a principal porta de entrada dos usuários na rede de atenção à saúde.

Desenvolve ações em nível individual, familiar e coletivo objetivando a promoção, prevenção, proteção e tratamento. Deve ser composta por equipe multiprofissional com médico, enfermeiro, auxiliar e/ou técnico de enfermagem e agente comunitário (BRASIL, 2017).

De forma geral, o enfermeiro, além da assistência direta ao paciente, também desempenha o papel de gerente da unidade básica, e o técnico, dentre várias funções, realiza atendimentos ao paciente, proporcionando maior liberdade de decisão e controle da evolução de saúde da população (CARDOSO TZ, et al., 2011; GALAVOTE HS, et al., 2016).

Percebe-se que a ESF se configura como campo rico para acadêmicos de enfermagem, pois, favorece o desenvolvimento de habilidades como a comunicação, tomada de decisão, gerenciamento do local e da equipe de trabalho e criação de vínculo com a população. Além disso, permite a vivência do trabalho em equipe, oportunizando as competências atitudinais, como forma de se relacionar com os colegas de trabalho e outras categorias profissionais (VEIGA GA, et al., 2020).

A Diretriz Curricular Nacional (DCN) do Curso de Graduação em Enfermagem, instituída pela resolução CNE/CES № 3 de 7 de novembro de 2001, determina que, além do conteúdo teórico e prático apresentado durante a graduação, as instituições, obrigatoriamente, devem incluir no currículo o estágio supervisionado, que deve cumprir $20 \%$ da carga horária total do curso (BRASIL, 2001).

A inserção dos acadêmicos nos serviços de saúde através do estágio permite colocar em prática a teoria aprendida em sala de aula e repensar sobre a prática assistencial, através de metodologia ativa de ensinoaprendizagem (ARAÚJO PN, et al., 2013).

Nesse contexto, tendo em vista elevada prevalência de profissionais de nível técnico entre a equipe de enfermagem e a relevância da integração do serviço de saúde com atividades de ensino, objetiva-se compreender a percepção e os desafios vivenciados pelos técnicos de enfermagem acerca da inserção dos acadêmicos de enfermagem no cenário de trabalho.

\section{MÉTODOS}

Pesquisa exploratória, descritiva com abordagem qualitativa. Este delineamento foi escolhido, pois permite realizar uma investigação interpretativo-formativa, que busca a compreensão do tema pesquisado, favorecendo o processo de descobrimento, por meio de análise, síntese de ideias e conceitos, com envolvimento de aspectos emocionais e contextuais (MINAYO MCS, 2014).

O cenário escolhido foi um município situado na Zona da Mata Mineira, composto por 20 equipes de ESF. Em parceria com uma universidade pública, oferece campos de aulas práticas e estágio aos acadêmicos de cursos da área da saúde.

Este município possui população de 79.388 habitantes (IBGE, 2019), dos quais $88,8 \%$ são cobertos pela ESF. A população do estudo foi composta por 20 técnicos de enfermagem que atuavam nestas ESF no período de coleta de dados (setembro a novembro de 2019).

Como critérios de inclusão elegeram-se: atuar como técnico de enfermagem de uma ESF e ter vivenciado atividades de ensino vinculadas a universidade pública, por pelo menos um semestre letivo. Devido a nunca 
terem vivenciado aulas práticas ou estágio supervisionado dos acadêmicos de graduação em enfermagem, dois técnicos foram excluídos da pesquisa. A amostra final foi composta por 18 técnicos de enfermagem.

Os dados foram coletados através de entrevista com roteiro semiestruturado elaborado pelas autoras do estudo. A primeira parte do roteiro apresentava perguntas de identificação do perfil dos participantes (nome, sexo, idade, tempo de formação, tempo de atuação na ESF e tempo de contato com acadêmicos de enfermagem).

A segunda parte continha os seguintes questionamentos: "A inserção dos acadêmicos de enfermagem na ESF interfere na sua dinâmica de trabalho?", "Como você considera a relação entre técnicos e acadêmicos de enfermagem?" e "Existe alguma vivência que te marcou (positiva ou negativa) que você gostaria de relatar?".

Após a organização das respostas, que foram gravadas e transcritas na íntegra, utilizou-se a técnica de Análise de Conteúdo, que segundo Bardin, pode ser compreendida nas seguintes etapas: pré-análise, exploração do material e tratamento dos resultados, inferência e interpretação (BARDIN L, 2011).

As entrevistas ocorreram em local reservado, garantindo conforto e privacidade. Para fins de preservação do anonimato, os técnicos de enfermagem foram referidos pelas letras TE procedidos do número correspondente à ordem em que foram realizadas as entrevistas.

O estudo foi conduzido segundo as normas da Resolução 466/2012 do Conselho Nacional de Saúde, tendo sido aprovado pelo Comitê de Ética em Pesquisa com Seres Humanos da universidade pública federal proponente da pesquisa, sob parecer $n^{\circ}: 3.516 .768$.

\section{RESULTADOS E DISCUSSÂO}

Quanto à caracterização dos participantes, os dados são apresentados na tabela 1.

Tabela 1 - Caracterização dos participantes da pesquisa, 2019.

\begin{tabular}{lll}
\hline Variáveis & $\mathbf{N}$ & $\%$ \\
\hline Sexo & & \\
\hline Masculino & 3 & 17 \\
Feminino & 15 & 83 \\
\hline Idade (anos) & & 33 \\
\hline $36-39$ & 6 & 44 \\
$40-49$ & 8 & 17 \\
$50-59$ & 3 & 6 \\
60 ou mais & 1 & \\
\hline Tempo de Formação (anos) & & 28 \\
\hline$<10$ & 5 & 66 \\
$10-19$ & 12 & 6 \\
$>=20$ & 1 & 72 \\
\hline Atuação na ESF (anos) & 3 & 11 \\
\hline$<1$ & 3 & 24 \\
$1-10$ & 13 & 35 \\
$>10$ & 2 & 41 \\
\hline Vivência em aulas práticas (anos) & & \\
\hline$<1$ & & 28 \\
$1-5$ & 6 & 72 \\
\hline Interferência no trabalho & 7 & \\
\hline Não & & \\
Sim & 5 & \\
\hline
\end{tabular}

Legenda: *Um entrevistado não soube responder este item.

Fonte: CRUZ JG, et al., 2020.

A partir da análise de conteúdo, emergiram as seguintes categorias: "O que a prática ensina?"; "Integração ensino-serviço: uma via de mão dupla" e "Acadêmicos x técnicos de enfermagem: desafios vivenciados". 


\section{O que a prática ensina?}

Esta categoria tem como objetivo explanar a importância da inserção dos acadêmicos no serviço, bem como destacar fatores que podem interferir na dinâmica de aprendizagem. Com base no conteúdo das entrevistas, ficou evidente que os técnicos de enfermagem enxergam a prática como uma forma de ensino que complementa a teoria.

"A prática também ensina muito. O que a gente vê é muita gente formando e que nunca fez. Porque pra mim, assim, pra pessoa mandar, ela tem que saber fazer. Tem que saber mandar e tem que saber fazer." (TE-5).

"Porque você pode saber tudo, pode saber toda técnica de uma punção, pode saber toda técnica de uma parada, mas se você não sabe colocar em prática aquilo ali, tudo ali é em vão." (TE-10).

Por meio da articulação entre teoria e prática, pretende-se que acadêmicos saibam o que fazer como fazer e o porquê fazer, através de um raciocínio clínico. Pinto TR e Cyrino EG (2015) relatam que o campo prático permite aos acadêmicos abordar de maneira integral e contextualizada as famílias que são atendidas pelo serviço de saúde, além de permitir que ampliem suas concepções do processo saúde-doença, possibilitandoos aprender fazendo.

"Eles são, assim, muito corajosos também, pegam pra fazer tudo, mesmo com um pouco de dúvida, mas põem a mão na massa sabe?" (TE-16).

"Teve uma aqui que foi tirar um ponto e eu vi, assim, que ela estava meio tensa, sabe? Meio nervosa. [...] Aí eu fui e tirei pra ela. Ai quando foi no outro dia, com outro paciente pra tirar ponto, eu chamei a mesma menina pra tirar. Expliquei pra ela direitinho, falei que ela ia conseguir, porque o ponto era fácil. $E$ do jeito que falei com ela, ela mesma fez e conseguiu tirar os pontos, sabe? Aí ela foi me abraçou, me agradeceu e tudo. Depois ela já tirava os pontos até sozinha, sabe?" (TE-5).

O desenvolvimento da coragem, destacado pelos técnicos acima, é um benefício que somente a prática proporcionará aos acadêmicos. Ao experienciar o ambiente de trabalho, adquirem familiaridade com 0 cenário, tendo oportunidade de superar eventuais medos e receios, proporcionando formação de profissionais com experiência e excelência. Esteves LSF, et al. (2018) entendem que esse momento é importante para os acadêmicos, pois oportuniza fortalecer sua prática, conquistar sua liberdade e autonomia, além de aumentar sua confiança para tomada de decisões, se posicionando enquanto enfermeiros. Outro aspecto positivo apontado pelos técnicos de enfermagem é a forma como a prática consegue aproximar os acadêmicos de outras categorias profissionais, criando espaços de reflexão.

"[...] é muito bom quando a gente trabalha em grupo, combina bem com os médicos, enfermeiros, os estagiários e com os agentes comunitários, porque se não, não dá nada certo." (TE-17).

"Acaba sendo uma relação de família, de equipe. Há respeito, há integridade, há força de vontade, companheirismo, atenção. [...] eles ajudam a gente e a gente ajuda eles. Ninguém sabe tudo né?" (TE-12).

"Mas depois elas vão vendo no decorrer do tempo, assim, que um depende do outro. Porque assim, [...] você depende do faxineiro, você depende da cantineira, você depende do técnico de enfermagem." (TE-10).

Ao encontro, pesquisa de Pinto TR e Cyrino EG (2015), destaca que um dos benefícios da inserção dos acadêmicos na prática é justamente o contato com outras categorias profissionais, sendo benéfico para reconhecer a atuação e o papel do outro e desenvolver a capacidade de trabalhar em equipe, principalmente multiprofissional. 
"Eles ajudam muito, pra mim é positivo, porque ajuda demais a equipe toda. [...] Às vezes a gente não dá conta e já deixa pra eles fazerem. Uma palestra, um grupo, né? [...] Tanto também na parte prática, às vezes saem pra medir uma pressão, fazer curativo, ajuda demais. [...] Vão para o lado da Enfermagem, das enfermeiras e fazem a parte de técnico também, faz curativo, faz pré-consulta, tudo que eu faço ela faz." (TE-18).

Percebe-se pelo depoimento acima que o serviço oferece a oportunidade de colocar em prática pilares importantes para a formação acadêmica, conforme disposto na Portaria n.ำ1721/1994 (BRASIL, 1994). A assistência ocorre através do cuidado direto ao paciente, a gerência engloba a gestão dos recursos da unidade, bem como o preenchimento de indicadores e metas e o ensino acontece por meio da formação de grupos educativos. Entretanto, alguns técnicos de enfermagem ressaltaram que a atuação dos acadêmicos é dependente de alguns fatores intrínsecos, como seu interesse, que poderá resultar em experiências positivas ou negativas.

"Acho que contribui, quando é um estudante que queira ajudar sabe? Quando é aqueles que não quer, não ajuda não, atrapalha um pouquinho. [...] Tem aqueles que preocupa, que fala 'Quer ajuda?', ou de uma forma está observando o que você está fazendo, ou pega pra fazer, tem interesse. Porque também toda hora você ficar 'Vamos ali e tal' chamando pra fazer alguma coisa não funciona, tem que vir deles o interesse mesmo." (TE-8).

Merhy E (2012) salienta que a produção do cuidado é dependente das conexões produzidas por todos os integrantes da equipe, incluindo os acadêmicos, implicando em uma postura favorável para trocas de conhecimento e um posicionamento de abertura para o encontro. Outro fator apontado pelos técnicos, que pode influenciar na experiência dos acadêmicos, é a postura do enfermeiro da unidade.

"O estagiário é o que o enfermeiro é. [...] O estagiário é a sombra do enfermeiro. Se $o$ enfermeiro prende, ele fica preso e te atrapalha mesmo. Agora se o enfermeiro solta, não, tá supervisionando, mas solta ele ali pra ele fazer, consegue desenvolver um bom trabalho. " (TE-7).

A forma como os acadêmicos entendem a profissão é dependente das influências recebidas. Sua primeira referência profissional é o professor, que Ihes transmite sua percepção e experiência. À medida que vão adquirindo conhecimento e convivência com as instituições de saúde, conseguem enxergar a profissão com seus próprios olhos e reformulam sua concepção inicial. No estágio, sua principal referência é o enfermeiro da unidade. Vasconcelos ACF, et al. (2016) apontaram que alguns entrevistados percebiam o interesse e disposição dos acadêmicos em desempenhar determinada função de cuidado, porém eles ficavam limitados a algumas atividades instituídas pelos seus preceptores (enfermeiros).

\section{Integração ensino-serviço: uma via de mão dupla}

Nesta categoria encontram-se os benefícios observados pelos técnicos de enfermagem acerca da inserção dos acadêmicos no serviço, tanto para o trabalho cotidiano como para a instituição que os acolhem. Nota-se pelos depoimentos que o auxílio prestado pelos acadêmicos é muito benéfico e importante para 0 serviço, ao ponto de sua ausência ser sentida durante o período de férias.

"O estagiário, assim, quando eles vão, a gente acaba sentindo falta, porque acaba acrescentando a equipe mesmo." (TE-6).

"Aí ajuda demais. Dezembro já está chegando é férias né? Ai já fico pensando que vai ficar sobrecarregado." (TE-9).

Pinto TR e Cyrino EG (2015), trazem que as vantagens da inserção dos acadêmicos em campo prático vão além daquelas conquistadas por eles, chegando a beneficiar a instituição que os acolhem e os usuários. Além de atuar nas atividades já desenvolvidas na unidade, os técnicos trouxeram que os acadêmicos contribuem para que serviços preconizados pelo Ministério da Saúde e deliberados pela Lei Orgânica da Saúde №. 8.080/1990 sejam proporcionados aos usuários (BRASIL, 1990). 
"Agregam e ajudam muito, porque criança ali, por exemplo, quando tem puericultura né? Quando não tinha eles (acadêmicos), era difícil, não fazia puericultura, só media a criança mais ou menos e colocava pra médica fazer o atendimento né?" (TE-3)

Vasconcelos ACF, et al. (2016) enfatizam que a falta de recursos humanos impossibilita o cumprimento de demandas assistenciais, como grupos educativos, e com a inserção dos acadêmicos tais atividades passaram a ser realizadas. Isso demonstra o retorno social por meio de uma universidade federal, cujo custos são pagos com dinheiro público. Além da interação com o serviço, muitos técnicos afirmam que surge uma relação de amizade e parceria com os acadêmicos.

"A gente se uniu aqui e ficamos mais próximas mesmo. No dia da despedida dela eu fique até triste, porque a gente acaba fazendo vínculo né." (TE-11)

"Eles conversam muito com a gente, eles perguntam se tão atrapalhando. Não tem aquela coisa de chegar, sabe assim, vai faz, não. Tudo que eles vão fazer eles perguntam se podem." (TE-2)

O ambiente de trabalho é um dos aspectos determinantes da qualidade da assistência prestada ao paciente, por isso é imprescindível que seja tranquilo e acolhedor. Tambasco LP, et al. (2017) afirmam que a satisfação no trabalho está diretamente relacionada ao processo de saúde-doença do trabalhador, pois este interfere também na sua vida pessoal, justificando a importância de se ter uma boa qualidade de vida no trabalho.

Outra importante percepção é o fato dos técnicos se reconhecerem como educadores na ESF. O processo de educar é visto como uma "via de mão dupla", onde eles têm a oportunidade de transmitir seus conhecimentos aos acadêmicos ao mesmo tempo que recebem atualizações.

Vasconcelos ACF, et al. (2016) interpretam essa troca de conhecimento como uma simbiose, onde ambos os lados são beneficiados, apresentando poder de influência um sobre o outro. Amestoy SC, et al. (2013) abordam que aprender e ensinar são ações complementares, ao mesmo tempo que se ensina, aprende, e ao mesmo tempo que se aprende, ensina, tornando rico a troca de saberes.

"Eles aprendem com a gente e a gente aprende com eles. Porque a cada ano que passa vem evoluindo modos diferentes de trabalhar, nas técnicas, no atendimento, na abordagem, como conversar também, ajuda muito na atualização." (TE-17)

"[...] vai adquirindo novos conhecimentos também. Até porque também como técnico eu já formei há muito tempo, a gente acaba ficando desatualizado em algumas partes." (TE-1)

Essa troca de conhecimentos torna-se importante quando nos atentamos a média do tempo de formação dos técnicos de enfermagem desta pesquisa (12 anos). A tecnologia e modernização trazem consigo uma enorme reciclagem das técnicas, produtos e maneiras de prestação do cuidado, por isso os acadêmicos também podem ser compreendidos como uma das fontes de atualização (PIRES DEP, 2013).

\section{Acadêmicos $\mathrm{x}$ técnicos de enfermagem: desafios vivenciados}

Esta categoria compila todos os principais desafios vivenciados pelos técnicos de enfermagem durante 0 encontro com os acadêmicos. Foi unanime, entre os técnicos de enfermagem, o reconhecimento do auxílio prestado pelos acadêmicos para a equipe e comunidade. Porém, destacaram a existência de alguns fatores que dificultam a dinâmica de trabalho, como a quantidade excessiva de acadêmicos, ao mesmo tempo, nas unidades.

"De forma negativa, quando tem aula prática é muita quantidade de acadêmicos, em quantidade. Porque os PSF's são pequenos, são casas, então quando tem aula, junta muito, aí acaba interferindo toda a equipe. É porque as vezes tem paciente lá e o médico tá atendendo e aí ninguém sabem quem é quem, as vezes os próprios pacientes, entendeu?" (TE-4) 
Para uma assistência de qualidade é necessário, além de outros fatores, uma estrutura física compatível com os serviços prestados. Trajaman A, et al. (2009) trazem que as precárias condições físicas e o pouco espaço dentro das unidades são pontos negativos apontados por profissionais de saúde que convivem com acadêmicos, demonstrando a necessidade de uma infraestrutura adequada para inserção do acadêmico no campo prático.

Pinto TR e Cyrino EG (2015) apontaram que muitas vezes é necessário que a equipe utilize de improvisação para receber os acadêmicos, numa tentativa de contornar a falta de espaço na unidade e minimizar os problemas.

Outros aspectos que prejudicam a dinâmica de trabalho, relatados pelos técnicos, são a falta de sensibilidade, por parte de alguns acadêmicos, quanto ao momento correto de realizar questionamentos acerca de alguma dúvida, além do nível de atenção demandada durante a rotina de trabalho.

A pesquisa de Vasconcelos ACF, et al. (2016) traz relatos semelhantes de profissionais de saúde que se sentem sobrecarregados com a inserção dos acadêmicos em campo prático, pois os consideram como um aumento de afazeres cotidianos.

"Porque assim, você tem que parar, tem que ensinar o estudante, aí acaba que atrapalha a gente a fazer as coisas né? Você tem que dar atenção e as vezes não consegue dar tanta atenção assim." (TE-14)

O desenvolvimento das habilidades práticas deve ser subsidiado pela universidade antes mesmo dos acadêmicos chegarem ao estágio, através de aulas práticas eficazes durante as disciplinas. Além da atualização das técnicas, é importante que elas sejam coerentes com a realidade das instituições de saúde, para que os acadêmicos consigam imergir na realidade do serviço traduzindo na prática a teoria aprendida. Vasconcelos ACF, et al. (2016) apontam que os profissionais conseguem enxergar essa separação existente entre a formação e a atuação, fazendo com que prática da sala de aula seja diferente da prática do serviço.

"O aluno dessa universidade, eles são muito focados na teoria. Teoria. Então assim, eles poderiam melhorar mais a prática. Buscar mais conhecimento na prática, pegar mais pra fazer na prática. Porque eles focam muito em teoria." (TE-4)

"Eu acho que tem uma falta de aprofundamento na técnica mesmo, sabe? Eles chegam muito cru tem hora [...]. Eles têm muita teoria, mas pouca prática." (TE-8)

A desvalorização profissional foi outro ponto levantado pelos técnicos, quanto ao sentimento que alguns acadêmicos afloraram neles durante o encontro.

"[...] sentindo que a gente, porque a gente é técnico e elas estavam no curso superior, ai sentia que era melhor do que a gente. Entendeu? Parecia assim, só porque elas faziam curso superior, já sabiam de tudo." (TE-5)

"[...] alguns estagiários já vêm achando que sabe tudo sim e como a gente já está na área há muito tempo, a gente falava 'Não é assim que funciona as coisas, não vai funcionar desse jeito' e eles falavam 'Tem que ser desse jeito, assim que é o certo'. A gente até chegava a tentar daquele jeito, mas aí via que não dava certo e voltava atrás." (TE-15)

Lage CEB e Alves MS (2017) afirmam que a diferença de reconhecimento existente entre as classes trabalhadoras em saúde é evidenciada pelo comportamento da sociedade moderna, na qual o cuidado assistencial não é visto com o mesmo valor que o tratamento medicamentoso.

Ribeiro IL (2013) enfatiza a importância de uma formação que auxilie o estudante a se posicionar, estreitar laços e não assumir uma postura de detentor do saber por possuir o conhecimento científico do seu trabalho, colocando-se em uma posição de poder.

Como limitação da pesquisa tem-se uma escassez de produção cientifica que apresentasse como tema os acadêmicos/estagiários de enfermagem relacionados a outras categorias profissionais além do enfermeiro. Sugere-se que mais pesquisas como estas possam ser desenvolvidas, como forma de enriquecer o conhecimento acerca do ensino-aprendizagem e a parceria universidade-serviço. 


\section{CONCLUSÃO}

Depreende-se que os técnicos de enfermagem reconhecem a importância de integrar os acadêmicos ao serviço, uma vez que entendem que a prática possibilita adquirir conhecimentos, aperfeiçoar habilidades técnicas e desenvolver atitudes profissionais. Concordam que os acadêmicos trazem benefícios para equipe e a instituição, através do desenvolvimento de atividades já inseridas no serviço e também no auxílio para fundamentação de atividades antes não realizadas. Outra percepção importante proporcionada pela pesquisa é a forma como os técnicos se reconhecem como educadores e sua disposição a assumir esse papel. Podemos dizer que o principal favorecido por essa parceria ensino-serviço é o paciente, foco central do trabalho realizado na ESF. Porém, os técnicos destacaram fragilidades que precisam ser revistas: a falta de interesse dos acadêmicos; a postura de alguns enfermeiros; quantidade excessiva de acadêmicos no campo prático; a ausência de desenvolvimento de habilidades técnicas prévias; e a desvalorização profissional sofrida por eles a partir de alguns acadêmicos. Percebe-se que tais fragilidades são passíveis de serem revistas pela instituição de ensino, resultando em melhorias na parceria ensino-serviço de saúde.

\section{REFERÊNCIAS}

1. AMESTOY SC, et al. Percepção dos enfermeiros sobre o processo de ensino aprendizagem da liderança. Texto Contexto Enfermagem, 2013; 22(2): 468-475.

2. ARAUJO PN, et al. A visão dos trabalhadores da atenção básica acerca da presença de estudantes de enfermagem. Revista da Escola de Enfermagem da USP, 2013; 47(3): 694-701.

3. BARDIN L. Análise de conteúdo. Lisboa: Edições 70; 2011, 223p.

4. BRASIL. Resolução CNE/CES no 3, de 7 de novembro de 2001. Institui Diretrizes Curriculares Nacionais do Curso de Graduação em Enfermagem. Brasília: Ministério da Educação, 2001.

5. BRASIL. Portaria no 2.436, de 21 de setembro de 2017. Aprova a Política Nacional de Atenção Básica, estabelecendo a revisão de diretrizes para a organização da Atenção Básica, no âmbito do Sistema Único de Saúde (SUS). Brasília: Ministério da Saúde, 2017.

6. BRASIL. Portaria n. ${ }^{1721 / 1994}$, de 15 de dezembro de 1994. Dispõe sobre o conteúdo e duração do curso de graduação em Enfermagem. Brasília: Ministério da Educação e do Desporto, 1994.

7. BRASIL. Lei n. ${ }^{\circ}$ 8.080. Dispõe sobre as condições para a promoção, proteção e recuperação da saúde, a organização e o funcionamento dos serviços correspondentes e dá outras providências. Brasília: Ministério da Saúde, 1990.

8. CARDOSO TZ, et al. Processo de trabalho de auxiliares e técnicos de enfermagem na Atenção Básica à Saúde. Revista Brasileira de Enfermagem, 2011; 64(6): 1087-1093.

9. COFEN. 2019. In: Conselho Federal de Enfermagem. Brasília: Enfermagem em números.

10. DUARTE JM, SIMÕES AL. A. Significados do trabalho para profissionais de enfermagem de um hospital de ensino. Revista Enfermagem UERJ, 2015; 23(3): 388-394.

11. ESTEVES LSF, et al. O estágio curricular supervisionado na graduação em enfermagem: revisão integrativa. Revista Brasileira de Enfermagem, 2018; 71(4):1842-1853.

12. GALAVOTE HS, et al. O trabalho do enfermeiro na atenção primária à saúde. Escola Anna Nery, 2016; 20(1): 90-98.

13. IBGE. 2019. In: Instituto Brasileiro de Geografia e Estatística. Brasília: Censo Demográfico.

14. LAGE CEB, ALVES MS. Debatendo a valorização da enfermagem: a voz dos enfermeiros da atenção primária à saúde. Revista enfermagem UFPE on-line, 2017; 11(3):1381-1387.

15. MERHY E. Saúde e direitos: tensões de um SUS em disputa, molecularidades. Saúde e Sociedade, 2012; 21(2): 267279.

16. MINAYO MCS. O desafio do conhecimento: pesquisa qualitativa em saúde. 14 ed. São Paulo: Hucitec; 2014.

17. PINTO TR, CYRINO EG. Com a palavra, o trabalhador da Atenção Primária à Saúde: potencialidades e desafios nas práticas educacionais. Interface - Comunicação, Saúde, Educação, 2015; 19(1): 765-777.

18. PIRES DEP. Transformações necessárias para o avanço da Enfermagem como ciência do cuidar. Revista Brasileira de Enfermagem, 2013; 66(n. spe): 39-44.

19. RIBEIRO IL. Aprendizagem na interação ensino-serviço-comunidade: a formação na perspectiva dialógica com a sociedade. Dissertação (Mestrado em Saúde Coletiva) - Centro de Ciências da Saúde. Universidade Federal do Rio Grande do Norte, Natal, 2013; 150 p.

20. VEIGA GA, et al. Metodologia ativa no estágio supervisionado de enfermagem: inovação na atenção primária à saúde. Revista Baiana de Enfermagem, 2020; 34(e34857).

21. TAMBASCO LP, et al. A satisfação no trabalho da equipe multiprofissional que atua na Atenção Primária à Saúde. Saúde em Debate, 2017; 41(2): 140-151.

22. TRAJMAN A, et al. A preceptoria na rede básica da Secretaria Municipal de Saúde do Rio de Janeiro: opinião dos profissionais de Saúde. Revista Brasileira de Educação Médica, 2009; 33(1): 24-32.

23. VASCONCELOS ACF, et al. Uma experiência de integração ensino-serviço e a mudança de práticas profissionais: com a palavra, os profissionais de saúde. Interface - Comunicação, saúde e educação, 2016; 20(56): 147-158. 